\title{
Validity and reliability of a novel subtalar joint axis of rotation locator measurement device
}

\author{
BH Kim, SC Lee, HD Lee, SY Lee* \\ From 4th Congress of the International Foot and Ankle Biomechanics (i-FAB) Community \\ Busan, Korea. 8-11 April 2014
}

\section{Context}

Inclination of the subtalar joint (STJ) in the transverse and sagittal planes may be highly associated with ankle sprain mechanisms. However, the validity and reliability of measuring inclination of the STJ axis of rotation (AoR) is not well established.

\section{Objective}

The purposes of this study were to: 1) examine the validity of a custom made instrument (locator) to measure the STJ AoR on the basis of the STJ inclination measured by X-ray, 2) to measure the intra-tester reliability of the locator.

\section{Design}

Cross sectional study.

\section{Setting}

Biomechanics laboratory.

\section{Participants}

Twenty nine healthy male (age: $22.89 \pm 9.11$ yrs; weight: $77.68 \pm 18.32 \mathrm{~kg}$; height: $176.16 \pm 14.16 \mathrm{~cm}$ ) and Nine health female (age: $25 \pm 8$ yrs; weight: $54.42 \pm 8.42 \mathrm{~kg}$; height: $164.33 \pm 7.67 \mathrm{~cm})$ subjects were recruited for this study.

\section{Intervention}

No Intervention.

\section{Main outcome measures}

Variables that were measured in this study were as follows: 1) Inclination of STJ AoR in the sagittal plane measured by radiographic images (Median MDXP-40 Inc, Korea) of the foot in the sagittal plane. In order to collect radiological images of the foot, subjects stood with a tandem position and the STJ was placed in neutral position. Sagittal plane inclination of the STJ AoR were further analyzed using ViewRex (TechHeim, Korea) per McClay's method [1]; 2) Inclination of the STJ AoR in the sagittal plane was measured by the locator; 3) Inclination of the STJ AoR in the transverse plane was measured by the locator. The anterior and posterior exit point were determined per Kirby's method [2]. Once the locator was aligned along two points, (anterior medial and posterior lateral exit point) a Digital Mini Protractor (WWC-TE Bevel Box, USA) was used to measure inclination angle. Pearson correlation was used to analyze the relationship of validity between radiographs and the locator measuring the STJ sagittal plane inclination. Intra Correlation Coefficient (ICC) was used to analyze day-to-day reliability of the locator.

\section{Results}

\section{Conclusion}

The locator may be used in the clinical setting since validity verified by correlation was high and the intratest correlation coefficient was large indicating consistent measurements. Along with the locator measurement, it is suggested that further study including motion analysis may provide more information regarding the relationship between inclination of STJ AoR and movement at the STJ.

Table 1 Intra-test reliability about STJ sagittal plane.

\begin{tabular}{ccccc}
\hline & \multicolumn{2}{c}{ Pearson correlation(.782) } & \multicolumn{2}{c}{ ICC(.907) } \\
\cline { 2 - 5 } & 1) X-ray & 2) Locator & T.1 & T.2 \\
\hline $\mathrm{M}^{\circ} \pm \mathrm{SD}^{\circ}$ & $42.50 \pm 2.76$ & $43.58 \pm 3.23$ & $42.22 \pm 1.79$ & $42.86 \pm 2.02$ \\
\hline
\end{tabular}

* Correspondence: sylee1@yonsei.ac.kr

Department of Physical Education, Yonsei University, Seoul, Korea 


\section{References}

1. McClay I, Bray J: The Subtalar Angle: A Proposed Measure of Rearfoot Structure. Foot Ankle Intl 1996, 17(8):495-502.

2. Spooner SK, Kirby KA: The Subtalar Joint Axis Locator. J Am Podiatr Med Assoc 2006, 96(3):212-219.

doi:10.1186/1757-1146-7-S1-A41

Cite this article as: Kim et al:: Validity and reliability of a novel subtalar joint axis of rotation locator measurement device. Journal of Foot and Ankle Research 2014 7(Suppl 1):A41.

Submit your next manuscript to BioMed Central and take full advantage of:

- Convenient online submission

- Thorough peer review

- No space constraints or color figure charges

- Immediate publication on acceptance

- Inclusion in PubMed, CAS, Scopus and Google Scholar

- Research which is freely available for redistribution

Submit your manuscript at www.biomedcentral.com/submit
Ciomed Central 